\title{
Expanding The Repertoire: Theory, Method and Language in Political Biography
}

\author{
R. A. W. Rhodes
}

\section{Introduction}

This essay poses three questions. Why is biography isolated from epistemological debates in political science? Are biographers confined to the archive and the tools of the historian? How do we explain our story? Biographers confront many issues specific to their particular art form (see for example Pimlott 1994, 169-61 and the chapters by Arklay and Bolton in this volume). But they can also confront core issues of theory, method and language central to the enterprise of political science. Yet, whether we look at biography through the spectacles of either mainstream or post-modern political science, both dismiss biography.

As an approach in mainstream political science, biography is criticised because it lacks analytical rigour and does not offer law-like generalisations. For example, Blondel $(1969,5)$ has consistently argued that both historical and case study methods are limited not only by lack of data but also by their inability to compare and explain systematically the structure and behaviour of governments. The case method is suitable for describing unique events and great men but it does not allow generalisations. It does not 'provide guidelines by which to abstract from reality the "critical" elements which would provide the material for comparisons on a large scale' (Blondel 1981, 67). In a similar vein, James (1992, 254) notes the many ministerial biographies, autobiographies, memoirs and diaries 'are often not much use to a student of Whitehall'. In the jargon of social science, quantitative, middle-range analysis is nomothetic analysis - that is, it is systematic and fosters generalisations - whereas biography (or case studies or a historical narrative) is idiographic analysis - that is, it is descriptive, focusing on the unique (Riggs 1962, 11).

If we take off our mainstream spectacles and wear those of postmodernism, the critique of biography is even more withering (if that is possible). The contrast between the mainstream political science and the post-modern project is sharp (see Bernstein 1991). The former strives after simplification and successive approximations to a given truth. The latter rejects such truth claims, accepting there are multiple realities and no foundations for asserting the superiority of one interpretation over another. Thus, Rosenau (1992, 118 and 120-21) includes a constructivist and contextualist theory of reality, in which reality is treated 
as a linguistic convention, among the core beliefs of postmodernism. In other words, 'to the extent that the mind furnishes the categories of understanding, there are no real world objects of study other than those inherent within the mental makeup of persons' (Gergen 1986, 141). Moreover, '[i]f language itself is relative and even arbitrary, and if language is the only reality we know, then reality is, at most, a linguistic habit'. 'There are no independently identifiable, real world referents to which the language of social description is cemented' (Gergen 1986, 143). So, 'all knowledge claims (all facts, truths, and validity) are "intelligible and debatable" only within their context, paradigm, or "interpretive community" (Fish 1989, 141) ... 'Reality is the result of social processes accepted as normal in a specific context'.

Stanley Fish (1991, 13-15) states the dilemma for biographers neatly. He argues there has been a shift from a discourse of the self as a conscious subject endowing the world with meaning to a discourse which explains meaning as the product of epistemes, paradigms or structures beyond the grasp of the conscious subject. The self is 'dissolved', so 'the notion of an intentional actor with a history and biography must dissolve too'. Any biography assumes 'notions of agency, personhood, cause and effect' that both govern our readings and are contested and contestable. What price the biography of an intentional actor in this post-modern world (and on this argument in historiography see Jenkins 1995 and citations)?

I want to contest both the mainstream and post-modern characterisations. I defend biographical studies by arguing that an interpretive approach deploying the notions of traditions, beliefs, and dilemmas and using the tools of the historian, the philosopher and the anthropologist can provide analytical narratives and diagnostic generalisations without making truth claims.

I now turn to each of my questions. First, I look at a possible interpretive theoretical approach to biography, focusing on the work of Mark Bevir (1999). Second, I look at methods, focusing on cultural ethnography and using the insights of Clifford Geertz (1973). Third, I examine the role of language and forms of story telling in writing narratives, focusing on Hayden White (1973). I do not claim any of these authors provide the right answer. I do argue these are major issues that biographers can address.

\section{Theory: Beliefs, Traditions, Dilemmas}

Interpretative approaches begin from the insight that to understand actions, practices and institutions, we need to grasp the relevant meanings, the beliefs and preferences of the people involved. As John Stuart Mill (1969 [1840], 119-20) remarked:

By Bentham ... men have been led to ask themselves, in regard to any ancient or received opinion, Is it true? And by Coleridge, What is the 
meaning of it? The one took his stand outside the received opinion, and surveyed it as an entire stranger to it: the other looked at it from within, and endeavoured to see it with the eyes of a believer in it ... Bentham judged a proposition true or false as it accorded or not with the result of his own inquiries ... With Coleridge ... the very fact that any doctrine had been believed by thoughtful men, and received by whole nations or generations of mankind, was part of the problem to be solved, was one of the phenomena to be accounted for.

Interpretive approaches are typically based on philosophical analyses of meaning in action. Meanings are beliefs and, to explain webs of beliefs, Mark Bevir (1999a) uses the concepts of tradition and dilemma. The concepts of belief, tradition, and dilemma distinguish interpretivism from other approaches to political science.

\section{Why Beliefs?}

As early as the 1950s, philosophers forcefully criticised positivism but political scientists often fail to take seriously the effects of rejecting a positivist notion of pure experience. Some cling tenaciously to the positivist idea that we can explain human behaviour by objective social facts about people and avoid interpreting beliefs. They try to avoid such interpretation by reducing beliefs to abstract and deductive models or to intervening variables between social facts and actions. However, once we reject the idea of pure experience, we cannot 'read-off' beliefs and desires from objective social facts (Bevir 1999a, 127-173). Instead, we must give prominence to the task of exploring the beliefs and meanings through which people construct their world. Because people do not have pure experiences, their beliefs and desires are inextricably enmeshed with theories. Thus, political scientists have to interpret beliefs as part of webs of beliefs, and locate these webs against the background of traditions and dilemmas.

\section{Why Traditions?}

The form of explanation we adopt for beliefs, actions, and practices revolves around the concepts of tradition and dilemma. The idea of a tradition captures the social context in which individuals both exercise their reason and act (Bevir 1999a, 174-220). A tradition is a set of understandings someone receives during socialisation. A certain relationship should exist between beliefs and practices if they are to make up a tradition. First, the relevant beliefs and practices should have passed from person to person and from generation to generation. The changes introduced by successive generations might even result in a tradition's beginning and its present-day formulation having nothing in common apart from the links over time.

Second, traditions should embody appropriate conceptual links. The beliefs and practices that one generation passes on to another should display minimal 
consistency. Traditions cannot be made up of purely random beliefs and actions that successive individuals happen to have held in common. This idea of tradition differs from that of Burkean political scientists who associate the term with customary, unquestioned ways of behaving or with the entrenched folklore of premodern societies (cf. Oakeshott 1962, 123 and 128-9). At the heart of Bevir's notion of tradition are situated agents using their local reasoning consciously and subconsciously to modify their contingent heritage.

\section{Why Dilemmas?}

The form of explanation we adopt for beliefs, actions, and practices revolves around the idea of dilemma as well as that of tradition. A dilemma captures the way in which situated agents are able to bring about changes in beliefs, traditions, and practices (Bevir 1999a, 221-264). A dilemma arises for an individual or group when a new idea stands in opposition to existing beliefs or practices and so forces a reconsideration of the existing beliefs and associated tradition. It is important to recognise that political scientists cannot identify dilemmas straightforwardly with what they take to be allegedly objective pressures within the world. What matters is the subjective or inter-subjective understandings of political actors. Of course, there is often much overlap between the pressures that political scientists believe to be real and the dilemmas that trouble political actors.

\section{Why Narratives?}

Our interpretive approach explains actions by reference to the beliefs and desires of actors, and it explains these beliefs by traditions and dilemmas. Political scientists explain many features of political life in this way already (and for several examples see Bevir and Rhodes 2006). Although the relevant beliefs and desires are many, complex, and hard to disentangle, political scientists still turn to them to explain human life. The term 'narrative' refers to this form of explanation; it describes the form theories take in the human sciences (Bevir 1999a, 252-62 and 298-306).

This approach has one major advantage for political biographers; they are off the hook of mainstream criticism. Mainstream political science's preference for a modernist-empiricist epistemology, with its core beliefs of comparison, measurement, law-like generalisation and neutral evidence, no longer provides the relevant yardsticks for judging the value of the political biographer's work. Bevir's interpretive approach with its focus on individual beliefs, actions and practices and use of the narrative form of explanation is consistent with the existing working methods of biographers. ${ }^{1}$ 


\section{Method}

The basic claim made for ethnographic method in general is that '[I]t captures the meaning of everyday human activities' (Hammersley and Atkinson 1983, 2). It encourages the researcher to get out there and see what actors are thinking and doing. It produces descriptive accounts valuable in their own right (Hammersley and Atkinson 1983, 237). It is exploratory and encourages fresh lines of thought. Research strategies and ideas can be adapted quickly. And for those who are so inclined, it can be used to test theory; by, for example, the detailed study of key cases (Hammersley and Atkinson 1983, 24).

For Clifford Geertz (1973, chapter 1), humans live suspended in the webs of significance they have spun. Anthropologists practice ethnology to discover the relevant weaves of meaning. Doing ethnography involves using techniques such as transcribing texts and keeping a diary. More important, it is about 'thick descriptions', about explicating 'our own constructions of other people's constructions of what they and their compatriots are up to'. The everyday phrase is 'seeing things from the other's point of view'. The key point is that ethnographers provide their own interpretation of what the informants believe they are up to, so these accounts are second or even third order interpretations.

Ethnographic description has four characteristics; it is interpretive; it interprets the flow of social discourse; it records that discourse commonly by writing it down; and it is microscopic. It is a 'soft science' that guesses at meanings, assesses the guesses and draws explanatory conclusions from the better guesses. Yet it is still possible for ethnographers to generalise. Theory provides a vocabulary with which to express what symbolic action has to say about itself. Although ethnography rarely aims at prediction, theory still has to 'generate cogent interpretations of realities past' and 'survive realities to come'. The task of the ethnographer is to set down the meanings that particular actions have for social actors and then say what these thick descriptions tells us about the society in which they are found. And this analysis is always incomplete.

An Englishman (in India) who, having been told that the world rested on a platform which rested on the back of an elephant which rested in turn on the back of a turtle, asked ... what did the turtle rest on? Another turtle. And that turtle? 'Ah Sahib, after that it is turtles all the way down'.

The ethnographer will never get to the bottom of anything. Ethnographic anthropology is a science 'marked less by a perfection of consensus than by a refinement of debate' — 'what gets better is the precision with which we vex each other'.

I agree with Fenno $(1990,128)$ 'that not enough political scientists are presently engaged in observation' and I adapt his stricture to political biography. Biography of living subjects is one opportunity for observation and the tools of ethnography 
provide the means. To the archival skills of the historian we must now add the participant observation and field notes skills of the anthropologist (on which see Sanjek 1990). ${ }^{2}$

\section{Language}

If interpretive theory guides us to and through 'the data', if ethnographic methods provide the tools for collecting data, then White (1973, 1978 and 1987) provides the guide on how to use the data to construct and explain the story. Specifically, he deals with the question of whether the plot and language of our narratives prefigure the explanation. Narratives are the stuff of all the human sciences where narratives are 'as much invented as found' so there is an 'irreducible and inexpungeable element of interpretation' and 'there can be no explanation without a story, so there can be no story without a plot' (White 1978, 51, 82 and 62). Explanation is a multifaceted skill similar to understanding a song; it is about connections, whether between words and music, ideas and institutions, individuals and traditions. It is about comparing webs of interpretation. So, to the question of the correct approach to history, White $(1973,4)$ answers:

... it does not depend upon the nature of the 'data' they used to support their generalisations or the theories they invoked to explain them; it depends rather upon the consistency, coherence and illuminative power of their respective visions of the historical field. This is why they cannot be 'refuted', or their generalisations 'disconfirmed', either by appeal to new data that might be turned up in subsequent research or by elaboration of a new theory interpreting the set of events that comprise their objects of representation and analysis.

White's (1973, chapter 1 and 1978, chapter 2) argues the choice of language or tropes prefigures both the story (and its plot) and, therefore, the explanation. Lacking a shared technical language, politics and history rely on familiar figures of speech (or ordinary language) to create meaning. So, in telling their story, historians give it meaning by the type of story they tell - 'emplotment'. White (1973) identifies four modes of emplotment or archetypal forms of storytelling - romance, tragedy, comedy and satire. We tell our stories by encoding them in one or other of these culturally recognised forms. This emplotment translates the past into a story and in the process explains to the reader what is happening. Since no given set or sequences of real events is intrinsically tragic, comic, farcical, and so on, but can be constructed as such only by the imposition of the structure of a given story type on the events, it is the choice of story type and its imposition upon the events that endow them with meaning (White 1987, 44). And in telling our story of an event, an institution, a person we confront the absurdity of the human condition and the importance of human aspiration. As 
White (1987, chapter 3) argues, we confront the nihilism of history by constructing shards of meaning from chaos. So, the historian, the biographer, and political scientists should abjure imposing order where there is none and instead focus on the notion of the sublime because human dignity and freedom emerge out of our reaction against the meaninglessness of history; we are transmuted into something higher, nobler, or more excellent.

These remarks are too brief to be described as even an introduction to White's work. They do serve two useful purposes, however. First, they show that all historical works, whether of a person, period or events, are 'constructed'. So, political biographies are often more about the author and his or her constructions than the ostensible subject. Second, White poses the question of the extent to which the choice of literary form predisposes the text to a particular form, of explanation. How we tell a life as a romance, a tragedy or whatever - becomes the explanation of that life. ${ }^{3}$

\section{Conclusion}

I have used the work of Bevir on interpretive theory, Geertz on cultural ethnography, and White on the analysis of narratives to provide answers to my questions on epistemology, method and language. There are no conclusions to this short piece because my answers are only illustrations. However, I have tried to make my examples relevant to practitioners of political biography for the same reasons we debate these topics in political science - they broaden our repertoire.

\section{ENDNOTES}

\footnotetext{
${ }^{1}$ For examples see Bevir 2002 on Sydney Webb, and Bevir 1999b on Annie Besant.

2 For an example of a biography based on participant observation see Watson (2002) on Paul Keating.

3 For an illustration of this argument compare Campbell's (2001 and 2003) chronological romance of Margaret Thatcher's rise from grocer's daughter to world leader with Seldon's (2004) thematic tale of Blair as tragedy.
} 